\title{
Experimental investigation of heat transfer characteristic of semi circular longitudinal vortex generators in rectangular channel
}

\author{
Ravindra F. Dunde* and Sunil B. Ingole \\ Mechanical Engineering Department, Savitribai Phule Pune University, PES ModernCollege of Engineering, Shivaji Nagar, Pune, India
}

Accepted 15 June 2016, Available online 20 June 2016, Special Issue-5 (June 2016)

\begin{abstract}
The vortex generators in the form of semi circular winglets were used in the present study to investigate heat transfer characteristics. These vortex generators can be mounted on the flat surface by either welding, embossing or punching. In this experiment punched $45^{\circ}$ inclined semicircular vortex generators were developed which were directly punched on longitudinal winglet. These vortex generators induced stream wise longitudinal vortices. These vortices disrupted the growth of the thermal boundary layer and results to heat transfer enhancement between the fluid and surfaces. In this experiment semi circular vortex without hole, with holes of 3, 5 and $7 \mathrm{~mm}$ diameters at centroid were used in in-line position and results were compared with each other. Measurements were carried out for a rectangular channel of an aspect ratio of $A R=1.12$, for a winglet transverse pitch $(S)$ to a longitudinal winglet height (e) ratio of $S / e=0.59$, and a winglet height $(e)$ to a channel height $(H)$ ratio of $e / H=0.24$. The Reynolds numbers considered were ranged from 16458 to 41147 . The results of punched semi circular longitudinal vortex generators with and without hole were compared with the smooth plate surface. The vortex generators with hole of $5 \mathrm{~mm}$ diameter at centroid show a more significant increase in heat transfer as compared to the vortex generators without hole and with 3 and $7 \mathrm{~mm}$ hole diameter. Results showed a 24.75-32.80\% increase in heat transfer and 25-33\% decrease in pressure drop due to the use of vortex generators with $5 \mathrm{~mm}$ hole at centroid position.
\end{abstract}

Keywords: Heat transfer, Punched semi circular vortex generators, Pressure drop.

\section{Introduction}

Increasing demands are placed on the performance of air fin tube heat exchanger used in air conditioning, power system, electronic chip cooling and aerospace, etc. for reasons of compactness, economy in manufacturing and operating costs, and energy conservation. The design limitations imposed upon different heat exchangers require new and innovative approaches to further reduce the volume, material cost, and flow noise. Because the air-side thermal resistance is dominant, even modest enhancements in the air-side thermal-hydraulic performance could lead to smaller, lighter, and more energy efficient systems. A variety of techniques of enhancing air side

Heat transfer such as wavy fin, louver fin and slotted fin, etc. usually lead to a larger pressure loss penalty while enhancing heat transfer. One of the best passive techniques is to use vortex generators to produce longitudinal vortices inducing strong swirling motion that serves to bring about the enhancement of heat transfer at a modest cost of the additional pressure loss. The basic principle of VGs is to induce secondary flow, particularly longitudinal vortices

*Corresponding author: Ravindra F. Dunde
(LVs), which could disturb or cut off the thermal boundary layer developed along the wall and remove the heat from the wall to the core of the flow by means of large-scale turbulence. Thus mechanism of heat transfer enhancement is based on flow separation and reattachment. In general, flow reattachment introduces a strong shear flow on the surface behind each rib or winglet, resulting in an effective disruption of the thermal boundary layer and thus the improvement of the heat transfer.Through the experimentation for the optimization of shape and angle of attack of winglet vortex generator in a rectangular channel for heat transfer enhancement it was found that RVG provides the highest heat transfer enhancement and pressure drop followed by the TVG and DVG due to having the largest area facing the flow of air. It was concluded that when the Reynolds number is low; variation of the angle of attack of the VG does not lead to the significant changes in the nusselt number. But at higher Reynolds number, this parameter is very crucial. VG at angle of attack $45^{\circ}$ possess the more heat transfer enhancement in comparison with the other angles of attack (Azita Abdollahi, et al, 2015).

The experiment for heat transfer enhancement of wavy finned flat tube by punched longitudinal vortex generators i.e. delta wing, rectangular wing, delta 
winglet pairs and rectangular winglet pairs and reported that delta winglet pairs is the best longitudinal vortex generators among these four configurations of vortex generators. The air-side heat transfer coefficient increases with the number of the delta winglet pairs punched on the fin surface which also leads to increase in pressure drop (Xiaoze Du, 2014).Punched longitudinal vortex generators in form of winglets in staggered arrangements were used to enhance heat transfers in finned oval tube heat exchanger. It was noted that staggered arrangement of the winglets was more effective than the in-line arrangement for heat transfer enhancement. Two staggered DWPs resulted in 20\% higher heat transfer enhancement with $14.5 \%$ lower additional pressure loss than three inline DWPs. (N.K. Mitra, et al, 2000). Heat transfer in a channel with PTVGs and PRVGs was measured and concluded that the averaged heat transferred from surfaces with PTVGs was higher than that of the PRVGs. It was also seen that at low Reynolds number the effects of attack angles and the distance to the punched winglet from the bottom of the channel on the heat transfer is insignificant (S. Caliskan, 2014).

Researcher carried out experiment to find the performance of plane and curved winglet (rectangular, trapezoidal and delta) vortex generators (VGs) with and without punched holes. It was found that the vortex generators with punched holes have better flow and heat transfer characteristics in laminar as well as turbulent region. Curved winglets VGs have lower flow resistance even though they have larger face area (Guobing Zhou, 2014). Comparison of the heat transfer characteristics of modified rectangular longitudinal vortex generator (LVG) obtained by cutting off the four corners of a rectangular wing with those of original rectangular LVG concluded that modified rectangular wing pairs (MRWPs) have better flow and heat transfer characteristics than those of rectangular wing (Chunhua Min, et al, 2010). Study of the effect of winglet thickness on convective heat transfer lead to conclusion that as thickness of the winglets increases there is increase in the overall heat transfer.It was also observed that the heat transfer is enhanced by $33 \%$ when single winglet is employed used and by $67 \%$ when a winglet pair is used (G. Biswas, et al, 2007).

Study of effects of different orientations of winglet arrays i.e. inline rows of winglet (IRW), staggered rows of winglet (SRW), common-flow down in series (CFD-CFD), common-flow up in series (CFU-CFU), combined (CFD-CFU) concluded that performance of CFU-CFU configuration is best in terms of heat transfer(Anupam Sinha, et al,2013).

Experimentation for heat transfer enhancement and simultaneously reduction in pressure drop in fin tube heat exchanger by using vortex generators in common flow up configuration for staggered tube banks and in-line tube banks concluded that staggered tube banks, gave the heat transfer enhancement by $30 \%$ to $10 \%$, and pressure loss was reduced by $55 \%$ to $34 \%$ while in case of in-line tube banks, these were found to be $20 \%$ to $10 \%$ enhancement in heat transfer and $15 \%$ to $8 \%$ reduction in pressure $\operatorname{drop}(\mathrm{K}$. Torii, 2002).

\section{Experimental Setup}

The experimental setup was designed and constructed at PES MCOE, Pune. The heat transfer experiments were conducted in an air rectangular channel system as shown in Fig.2. The experimental setup consists of a test section with a wire cut of $1.5 \mathrm{~mm}$ depth and $0.54 \mathrm{~mm}$ width, a centrifugal blower, honey comb ,vortex generators(with and without holes), anemometer for measuring the velocity of air, control panel with dimmer stat and temperature indicator and digital pressure difference measuring device. Twelve $\mathrm{k}$ type thermocouples were used to measure the average temperature of test plate which were located on the top side of test plate having $25 \mathrm{~mm}$ spacing.

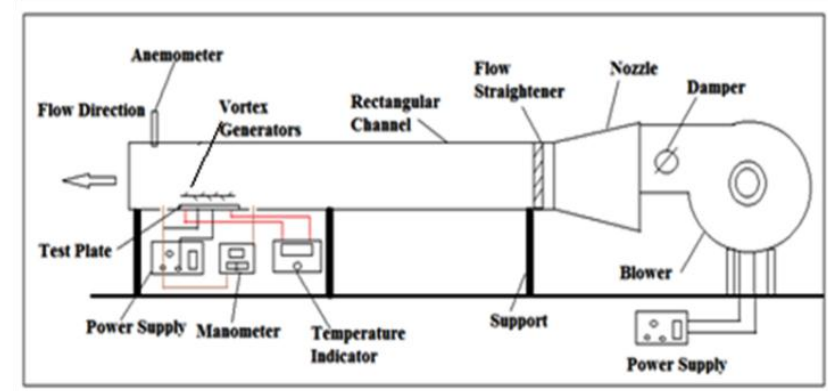

Fig.1 Block diagram of Experimental Set-up

Air was drawn in by a variable speed and passed through the rectangular duct as test section of the channel. The duct inner cross section dimensions were $280 \mathrm{~mm}$ (wide) and $250 \mathrm{~mm}$ (height) and $2800 \mathrm{~mm}$ long. The channel was constructed with $5 \mathrm{~mm}$ thick mild steel sheet.

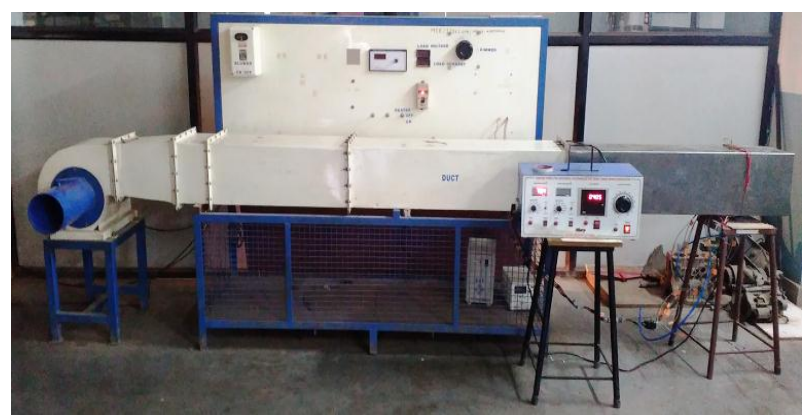

Fig.2 Actual Experimental setup

A square slot of $150 \times 150 \mathrm{~mm}$ was cut at the bottom of the duct for insertion of aluminium test plate of same dimension and plate heater. The bottom side of plate heater was insulated by asbestos sheet to avoid heat loss from bottom side of test plate The plate heater was made of nichrome coil as heating element of dimension $150 \mathrm{~mm} \times 150 \mathrm{~mm}$ was used to heat the aluminium plate at the desired temperature. A test plate of 
dimension $150 \mathrm{~mm} \times 150 \mathrm{~mm}$ and $5 \mathrm{~mm}$ thickness made of aluminium was used for this experiment over which five slots of $150 \mathrm{~mm}$ and $25 \mathrm{~mm}$ spacing were cut for the insertion of longitudinal winglets. The punched semi circular longitudinal winglets were mounted on top of aluminium plate to enhance the convective heat transfer. The averaged heat transfer coefficient on the plate surface was measured for various rates of air flow through the duct. The longitudinal winglets were made of high conductivity aluminium material. Each of the longitudinal winglets was fabricated from $0.5 \mathrm{~mm}$ thick and $150 \mathrm{~mm}$ long aluminium plate.

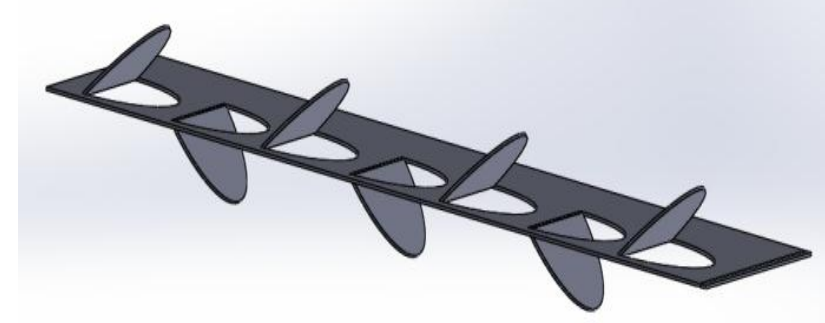

Fig.3 Single Semi circular longitudinal winglet

The longitudinal winglets were fitted into the slots which were created on the top of aluminium test plate. The thermal contact resistance due to the slot created on the test plate introduced a minor conservative preference so thermal conducting paste was applied in the slots. The minimum distance between the two longitudinal winglets was $25 \mathrm{~mm}(\mathrm{~S})$. The punched length of the semicircular winglet was $15 \mathrm{~mm}$ (c) while the distance between the two punched winglets was $20 \mathrm{~mm}(\mathrm{~g})$.

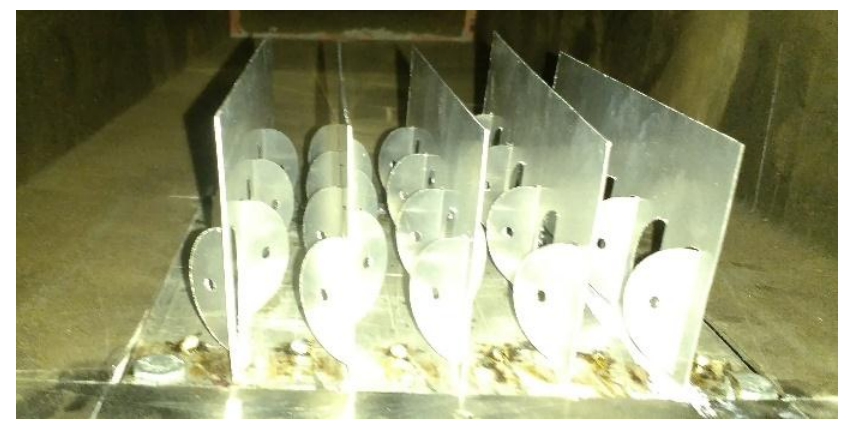

Fig.4 Rectangular channel with semi circular vortex generators

The air velocity was measured by the AM 4201-type anemometer at the open end of the channel. The inlet and outlet temperatures of the channel air were measured in different locations of the channel by using a K-type thermocouple. All of these thermocouples were connected to a digital control system.

\section{Experimental Procedure}

A constant power input of 30 watt was supplied and a constant velocity (Initially $1 \mathrm{~m} / \mathrm{s}$ ) was adjusted. A temperature of air at inlet and exit of test section and at different locations on a test plate were recorded with temperature indicator. An initial period of 30-35 minutes required to reach a steady state condition (which was considered to be attained, when the temperatures indicated by the thermocouples did not vary with more than $\pm 0.5^{\circ} \mathrm{C}$ within a period of about 2 3 minutes) The pressure drop across the test plate was measured by digital pressure difference measuring device. After collecting a set of data at a steady state conditions, a new set of data was collected with a same velocity for different arrangements (test plate without hole winglets and with in-line 3,5 and $7 \mathrm{~mm}$ holes) Another set of data is obtained by varying the velocity of air $(1 \mathrm{~m} / \mathrm{s}$ to $2.5 \mathrm{~m} / \mathrm{s})$.

\section{Formulae used for calculations}

The convection heat transfer can be written as:

$$
\mathrm{Q}=\mathrm{h} \times \mathrm{A} \times\left(\mathrm{T}_{\mathrm{S}}-\mathrm{T}_{\mathrm{b}}\right)
$$

In which

$$
\begin{gathered}
\mathrm{T}_{\mathrm{b}}=\left(\mathrm{T}_{\mathrm{o}}+\mathrm{T}_{\mathrm{i}}\right) / 2 \\
\mathrm{~T}_{\mathrm{s}}=\left(\mathrm{T}_{\mathrm{s} 1}+\mathrm{T}_{\mathrm{s} 2}+\mathrm{T}_{\mathrm{s} 3} \cdots+\mathrm{T}_{\mathrm{s} 12}\right) / 12
\end{gathered}
$$

Where $\mathrm{T}_{\mathrm{s} 1-12}$ the local surface temperatures and the average surface temperature is calculated from 12 locations, The Nusselt numbers $(\mathrm{Nu})$ are estimated as follows:

$$
\mathrm{Nu}=\left(\mathrm{h} \times \mathrm{D}_{\mathrm{h}}\right) / \mathrm{k}
$$

The Reynolds number based on the hydraulic diameter of the channel is given by

$$
\operatorname{Re}=\left(\rho \times u \times D_{h}\right) / \mu
$$

Where $D_{h}=2 \mathrm{WH} /(\mathrm{W}+\mathrm{H})$ is the channel hydraulic diameter.

Friction factor, $\mathrm{f}$ can be written as

$$
\mathrm{f}=\frac{\Delta \mathrm{P}}{\left(\frac{\mathrm{L}}{\mathrm{D}_{\mathrm{h}}}\right) \frac{\rho \mathrm{V}^{2}}{2}}
$$

Where, $\Delta \mathrm{P}$ was pressure drop across the length of channel, L.

\section{Results and Discussion}

The experiment was performed for semi circular longitudinal winglet type vortex generator with hole of 3,5 and $7 \mathrm{~mm}$ at centroid and without hole at $45^{\circ}$ angle of attack. The results of punched semi circular longitudinal vortex generators with and without hole were compared with the flat plate. The experiment was conducted with different Reynolds Number. The results on PSCVGs with different parameter are 
presented in this paper, the Nusselt numbers obtained under turbulent flow conditions for semi circular-type vortex generators, with different Reynolds Number (16458 to 41147) and distances of punched winglet from the channel bottom $(b / e=0.066)$, and attack angle $\alpha=45^{\circ}$ are presented.

\subsection{Nusselt Number $(\mathrm{Nu})$}

The variation in nusselt number at different $\operatorname{Re}(16458$ to 41147) for different winglets are shown in fig. 5 . With the increase in the Reynolds number (Re), the nusselt number $(\mathrm{Nu})$ increases for all the cases i.e. flat plate without winglets, with winglets and winglets with holes. It is observed that the $\mathrm{Nu}$ number gradually increases with increasing Re number in all the cases. $\mathrm{Nu}$ number for test plate with winglets having in lined $5 \mathrm{~mm}$ diameter at the centroid of semi circular vortex increases $24.74 \%-32.80 \%$.This is due to the increase in turbulence created by holes on vortex generators. While the increase in $\mathrm{Nu}$ number in case of winglet with 3 and $7 \mathrm{~mm}$ diameter hole was in the range of $12.6 \%-14 \%$ and $18.30-28 \%$ respectively.

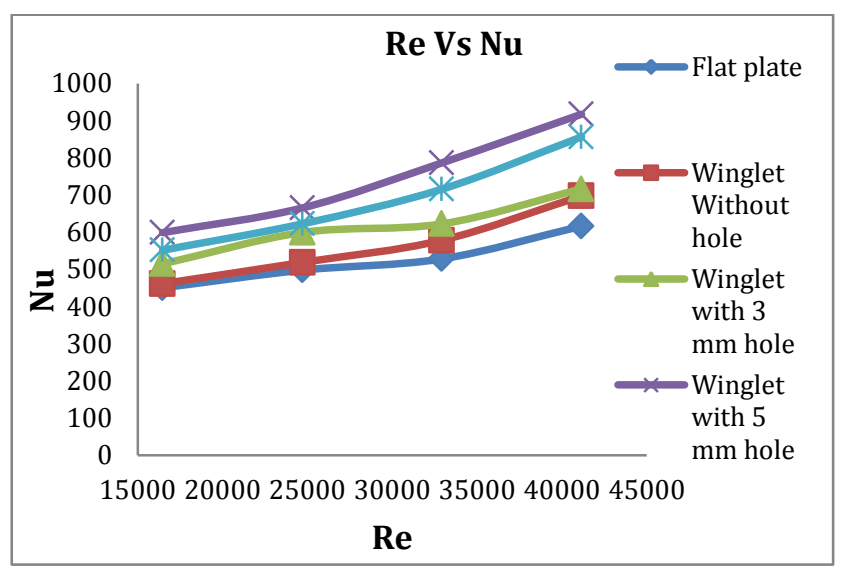

Fig.5 Variation of Nusselt Number $(\mathrm{Nu})$ with varying Reynolds Number (Re)

\subsection{Nusselt Number Ratio (Nua/Nuo)}

Fig.6 shows the relationship between Nusselt number ratio (Nua/Nuo) and Reynolds number (Re).It can be seen that $\mathrm{Nu}_{\mathrm{a}} / \mathrm{Nu}_{\mathrm{o}}$ of the channel with PSCVGs with hole and without hole increases as the Reynolds number values increased. The shorter distance of the punched winglet from the channel bottom makes disturbance at the boundary layer more effectively and provides a better air flow mix which leads to increase in heat transfer.

The heat transfer enhancement from the semi circular vortex generator with hole was more significant than that of the without hole. For the PSCVGs without hole, the Nusselt number ratio varied from 1.02 to 1.13 with Re increasing from 16458 to 41147 for the PSCVGs with hole of 3 and $7 \mathrm{~mm}$ diameter, $\mathrm{Nu}_{\mathrm{a}} / \mathrm{Nu}_{\mathrm{o}}$ values changed from 1.14 to 1.28 and 1.22 to 1.38 while highest increase in $\mathrm{Nu}_{\mathrm{a}} / \mathrm{Nu}_{\mathrm{o}}$ was observed for PSCVGs with hole of $5 \mathrm{~mm}$ diameter $(1.32$ to 1.48) for the same Reynolds number and the same heat input of 30 watt.

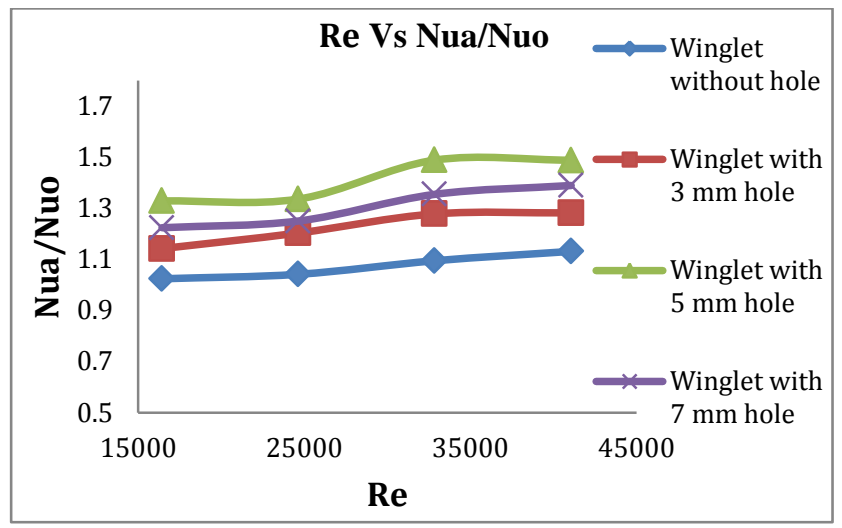

Fig.6 Variation of Nusselt Number ratio (Nua/Nuo) with varying Reynolds Number (Re)

\subsection{Heat Transfer Coefficient (h)}

From Fig.7 it can be seen that heat transfer coefficient (h) increased with increase in Reynolds number in all the case which were considered for the experimentation. Heat transfer is increased by $2.38 \%$ to $11.60 \%$ in case of test plate with winglets without hole, $12.46 \%$ to $14 \%$ in case of test plate with winglets of in-line $3 \mathrm{~mm}$ hole diameter, $24.75 \%$ to $32.80 \%$ in case of test plate with winglets of in-line $5 \mathrm{~mm}$ hole diameter and $18.3 \%$ to $28 \%$ in case of test plate with winglets of in-line $7 \mathrm{~mm}$ hole diameter as compared with flat plate.

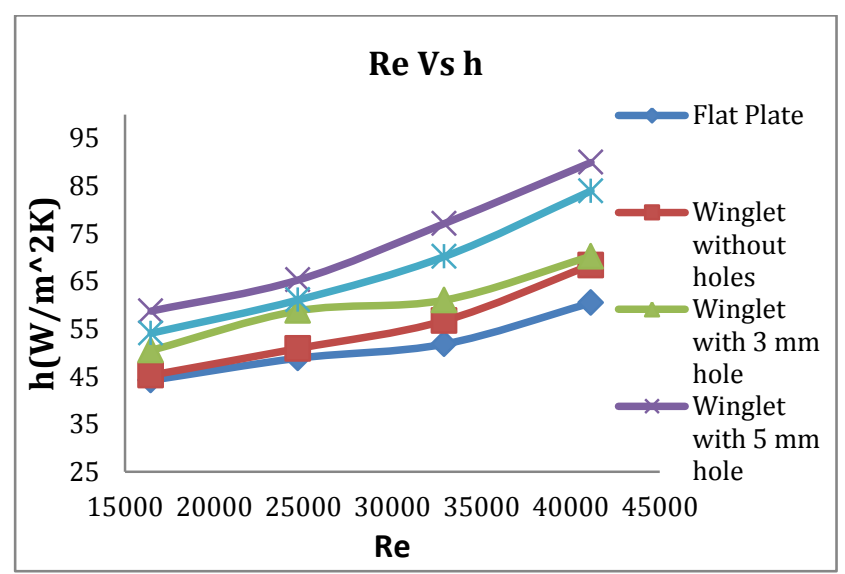

Fig.7 Variation of heat transfer coefficient (h) with varying Reynolds number (Re)

\subsection{Pressure Drop $(\Delta P)$}

Fig.8 shows that increase in Reynolds number (Re) leads to increase in pressure drop in all type of winglets i.e. with and without hole at centroid but it was observed that test plate with winglets of $7 \mathrm{~mm}$ diameter gives minimum pressure drop as compared to the winglets without and with hole of 3 and $5 \mathrm{~mm}$ diameter. Increase in diameter of hole present at 
centroid position offers minimum resistance to the flow of air which ultimately responsible for reduction in pressure drops. It was observed that winglets without holes offered higher pressure drop because of maximum resistance to the flow of air.

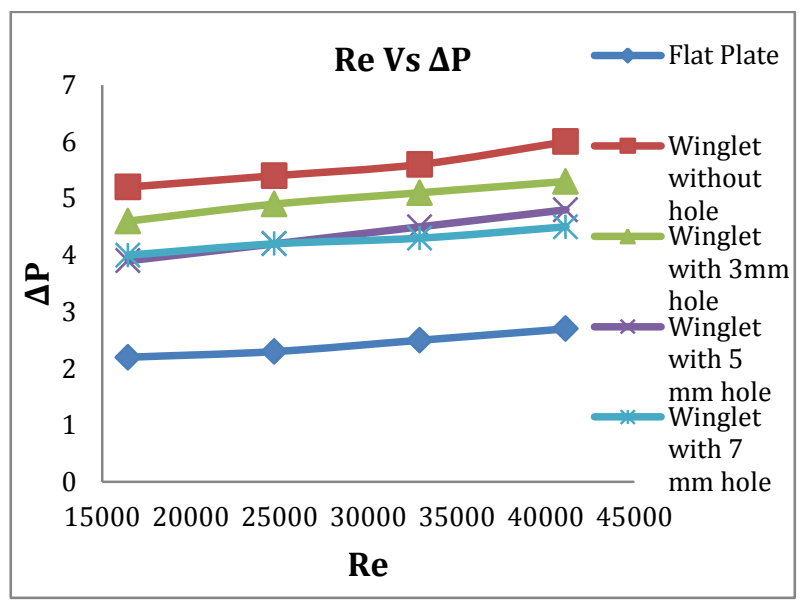

Fig.8 Variation in pressure $\operatorname{drop}(\Delta \mathrm{P})$ with variation in Reynolds number (Re)

\subsection{Friction Factor Ratio $(f a / f o)$}

Variations of the friction factor ratio fa/fo vs. the Reynolds number for semi circular vortex generators with and without hole are shown in Fig.9.

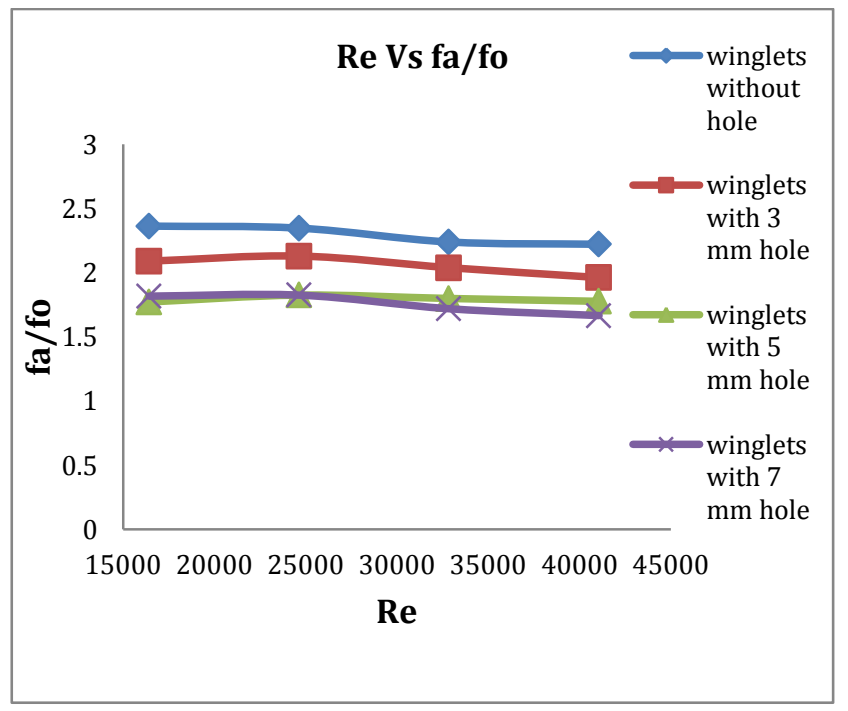

Fig.9 Variation in friction factor ratio (fa/fo) with varying Reynolds number (Re)

The friction factor found by using the vortex generators was observed to be higher than that of the smooth plate for all cases studied, because of the suppression of the viscous sub-layer. This can be attributed to flow blockage and the act caused by the reverse flow due to the presence of the vortex generators shows that increase in Reynolds number results in decrease in friction in all the cases. The friction factor for vortex generators without hole was much higher than vortex generators with hole and this was decreased more significantly with increased in Reynolds number as compared to lower Reynolds number. Friction factor observed in case of 5 and $7 \mathrm{~mm}$ hole vortex generators was nearly equal.

\section{Conclusions}

An experimental investigation of heat transfer characteristics in a rectangular duct without hole and with hole of 3,5 and $7 \mathrm{~mm}$ diameter with in-line position on PSCVGs under varying Reynolds number have been performed. The following conclusions have been drawn

1) The PSCVGs with and without hole arrangements had significantly enhanced the heat transfer rate, in comparison to a smooth plate surface without winglets. The heat transferred from surfaces with hole in PSCVGs was higher than that of the PSCVGs without hole.

2) The VGs which have smaller face area, smaller holes tend to give better thermal performance such as $\mathrm{d}=5 \mathrm{~mm}$ for the varying Reynolds numbers.

3) The hole in semi circular vortex generators decreases the flow resistance and reduces pressure drop but the optimal diameter of the hole must be matched with the VG face area.

4) The PSCVGs with $7 \mathrm{~mm}$ hole at centroid have low pressure drop as compare to PSCVGs without hole winglet and with 3 and $5 \mathrm{~mm}$ hole winglets and this result is more significant at higher Reynolds number.

5) There is no considerable friction factor variation in case of PSCVGs with 5 and $7 \mathrm{~mm}$ diameter hole.

\section{References}

Azita Abdollahi, Mehrzad Shams,(2015), Optimization of shape and angle of attack of winglet vortex generator in a rectangular channel for heat transfer enhancement, Applied Thermal Engineering, 81, 376-387.

Xiaoze Du , Lili Feng, Li Li, Lijun Yang, Yongping Yang, (2014) Heat transfer enhancement of wavy finned flat tube by punched longitudinal vortex generators, International Journal of Heat and Mass Transfer, 75 ,368-380.

Y. Chen, M. Fiebig, N.K. Mitra,(2000) Heat transfer enhancement of finned oval tubes with staggered punched longitudinal vortex generators International Journal of Heat and Mass Transfer, 43, 417-435.

S. Caliskan, (2014) Experimental investigation of heat transfer in a channel with new winglet-type vortex generators, International Journal of Heat and Mass Transfer, 78, 604-614.

Guobing Zhou,Zhizheng Feng,(2014),Experimental investigations of heat transfer enhancement by plane and curved winglet type vortex generators with punched holes, International Journal of Thermal Sciences, $78,26-35$

Chunhua Min , Chengying Qi, Xiangfei Kong, Jiangfeng Dong, (2014), Experimental study of rectangular channel with modified rectangular longitudinal vortex generators, International Journal of Heat and Mass Transfer, 53, 3023-3029.

S.R. Hiravennavar , E.G. Tulapurkara , G. Biswas, (2007), A note on the flow and heat transfer enhancement in a channel with built-in winglet pair, International Journal of Heat and Fluid Flow, 28,299-305.

Anupam Sinha, K. Ashoke Raman, Himadri Chattopadhyay, Gautam Biswas,(2013), Effects of different orientations of winglet arrays on the performance of plate-fin heat exchangers, International Journal of Heat and Mass Transfer, 57, 202-214.

K. Torii , K.M. Kwak, K. Nishino, (2002), Heat transfer enhancement accompanying pressure-loss reduction with winglet-type vortex generators for fin-tube heat exchangers, International Journal of Heat and Mass Transfer , 45,3795-3801. 